\title{
TOWARDS A SUSTAINABLE, COHERENT AND APPROPRIATE CHILD WELFARE WORKFORCE IN SOUTH AFRICA
}

\section{Jeanette Schmid}

\section{INTRODUCTION}

South African welfare, and especially child welfare, has perennially been described as in crisis (Schmid, 2010). One feature of this crisis has been human resource challenges, in particular the ongoing shortage of suitably qualified social workers. Indeed, social work has been declared a scarce skill in South Africa. In 2011 the author studied trends over the decade 2001-2010 in South African child welfare and the dynamics behind these trends. In this research the participants reported that the crisis had shifted into an acute phase. Comprehensive and urgent intervention, including in the area of personnel, was required to prevent a collapse of child welfare services. The human resource issue was no longer identified simply as there being too few social workers. Rather, an increasingly diversified child welfare workforce was emerging, but the training, employment conditions, accreditation and recognition of various cadres of child welfare workers were unclear. This was causing tension in the field of child welfare. There was also extreme dissatisfaction with the (under-)responsiveness of the government to the situation.

The author was able to find little in the international literature regarding child welfare workforce issues. One article by Sar, Bledsoe, Sullivan, Weeks, Fox, Barrett, Wadlington and Cashwell (2008) talks about a child welfare workforce, but appears to focus exclusively on social workers. Frost and Parton (2009) refer to a children's social care workforce made of up integrated teams that include social workers alongside health and education professionals. In Anglo-American child protection systems, child and youth workers function alongside social workers, particularly with regard to residential care. (Freymond and Cameron (2006) have offered three typologies of child welfare systems, viz. child protection, family services and community care. The child protection orientation is typical of Anglophone systems). Melpignano and Collins (2003) thus suggest that youth development principles should be included in the training curriculum of child welfare workers. While social workers and child and youth workers may specialise, taking on the role, for example, of family support, foster care support or probation work, there appears otherwise to be little professional differentiation in Anglo-American child welfare. It is not clear who forms the child welfare workforce within the European family service systems. Volunteers do have a formal role in Swedish child welfare (Andersson, 2006). In South Africa, however, there seems to have been a range of service providers engaging with vulnerable children and their families.

This article outlines how the trend regarding workforce issues was described by the study participants. It further delineates the concerns that must be responded to by child welfare agencies, educational institutions and government as a matter of priority. The shift to considering a child welfare workforce rather than focusing on a single profession presents an important opportunity for the field. For example, while child and youth work forms a subsection of child welfare more broadly, the developments regarding a child welfare workforce are pertinent to child and youth care workers as they find and assert their position within this broader cadre of service providers. 


\section{THE STUDY}

The research focus was on establishing what participants perceived as the trends in child welfare over the previous decade as well as to identify what they saw as the drivers behind these trends.

The study, using a mixed method complemented with a reflexive methodology (Alvesson \& Skoldberg, 2000), comprised three concurrent prongs: interviews with representatives of national child welfare organisations; questionnaires to directors of child welfare agencies and to child welfare instructors at universities; and a literature scan of articles pertaining to South African child welfare. Eight persons - an academic, a child welfare advocate and representatives of five national child welfare organisations - participated in the interviews, a purposeful sampling approach being employed. The questionnaire was sent to all university social work departments and directed to child welfare instructors (individuals responsible for teaching child welfare-related classes or modules) and to the directors of all the affiliates of Child Welfare South Africa. For the literature scan, the researcher identified 155 child welfarerelated articles in the local journals, Social Work/Maatskaplike Werk and Social Work Practitioner Researcher, and using the search words, "child welfare", "child protection", and "child maltreatment", accessed 131 articles through Scholars Portal relating to South African child welfare in the period under review. These various sources of information were used to triangulate the data.

The questionnaire items formed the basis of the interviews. In the interviews the qualitative approach allowed in-depth examination of the issues explored in the questionnaires. Themes in the interviews, questionnaires and article topics were highlighted through the application of content analysis. Through a process of member checking, the interviewees reviewed the transcripts and confirmed that the initial analysis of trends and drivers conformed to the information they had provided to the researcher. The reflexive methodology used is an iterative and hermeneutic approach in which the researcher continually interrogated the meaning behind the research tools chosen, the responses/outcomes elicited and the interpretation of the results.

The results of the questionnaires do need to be treated with some caution: while six child welfare instructors from 17 of the university social work departments approached responded, only a limited number of responses (12) were received out of 250 sent out to the child welfare directors. Potentially these directors were overwhelmed with their daily responsibilities and/or did not see the research as relevant. The analysis of the academic research highlighted trends in the research agenda, but drivers behind these trends were inferred. Another limitation is that the views of government representatives were not polled, the study reflecting only the opinions of practitioners and academics.

The issues regarding a child welfare workforce emerged primarily from the interviews conducted. The responses to the questionnaires supported what was said in the interviews with regard to the shortage of social workers and the crisis in child welfare. Issues relating to a child welfare workforce were not addressed. From the literature scan, it was evident that sexual abuse, the needs of youth and the effects of the HIV/AIDS crisis formed the research agenda of academics examining South African child welfare. A minority of articles spoke to the role of social workers, for example, examining how statutory social work fitted into a developmental social welfare model or the discretion of social workers regarding possible interventions in the context of the new Children's Act (No. 38 of 2005 as amended in 2008). The issues discussed in this article are thus to be sourced back mainly to the interview content. These include an 
emergent child welfare workforce, drivers behind these trends and the steps needed to provide for a competent, consolidated, diverse and sustainable workforce.

\section{AN EMERGING CHILD WELFARE WORKFORCE}

The participants highlighted that a child welfare workforce, distinct in character from the traditional child welfare workforce, was emerging.

Three issues crystallised out of the study regarding an appropriate child welfare workforce:

- the shortage of skilled social workers;

- the multiplicity of emerging professions; and

- the role of volunteers.

\section{THE SHORTAGE OF SKILLED SOCIAL WORKERS}

\section{A SHORTAGE OF SOCIAL WORKERS}

The participants noted that there was "a dearth of qualified social workers". Indeed, "the human resource problems are worse than they were". Not only were there insufficient numbers of social workers, but there was a retention problem. This had affected NGOs in particular as novices who often receive a basic postgraduate training in child welfare agencies were reportedly frequently absorbed into government, where better working conditions, including higher salaries, are offered: "They start their working career in NPOs but as soon as the Department has a spot they leave". Even with the advantages it had compared to NGOs, the government could also not recruit sufficient numbers of social workers, and many social workers left for positions in the private sector or for work overseas. The government's retention and recruitment strategy had not adequately addressed the participants' concerns. It was not only salaries that impacted on retention, but also working conditions more broadly. These included increased demand; being overwhelmed by administrative tasks - "Everyone seems to be drowning in swamps of paper"; blockages in the courts - "There are huge backlogs regarding cases and huge problems regarding court orders"; and working with inadequate infrastructure, such as not having cars or the requisite driving licenses should cars be available, no phones and offices not necessarily being close to clients. Social workers were also personally confronted with social ills such as poverty and HIV/AIDs, but were nonetheless required to support clients dealing with these issues. Retention issues, linked to poor salaries, minimal professional acknowledgement and challenging working conditions, have also been identified in the literature as exacerbating the situation of too few social workers (Briede \& Loffell, 2005).

\section{CONCERNS REGARDING THE QUALITY OF SOCIAL WORKERS}

A further area of concern highlighted in the study was the quality of social workers. Participants felt that new graduates often lacked the necessary compassion, seemingly having chosen social work - following the reintroduction of social work study grants in the mid 2000s - simply as a way of gaining a graduate qualification. "There are people on social work bursaries who do not necessarily want to study social work but needed the bursary to get to university"; "Most of the younger social workers... lack any passion for their work or for children"; "I am concerned about the lack of empathy, especially when you see a social worker casually walk past a crying child". Additionally, participants believed that social work graduates had been ineffectively and inappropriately trained, leaving university without the skills needed to implement a developmental social welfare approach and lacking basic 
administrative competencies. "On the varsity level it is not clear if they are even teaching multidisciplinary work, assessment or work with child and youth care workers."; "It does not appear that they know the values of social work and are often not able to conduct an adequate interview, develop and carry out a plan of action with the family or write a structured report that follows a logical format or thought process". Furthermore, novice social workers had not been adequately equipped to deal with local conditions: "The theoretical training in social work and the practice in South Africa is often disjointed. Often the theorising of social work is based on international practice, influenced by American and European models... Our training makes our social workers popular and in demand in international settings such as the United Kingdom, but it also creates a 'gap' for those who work in the country and in local communities". That the majority of middle managers are inexperienced had the knock-on effect that beginning social workers were not receiving the guidance or role modelling that seasoned supervisors had previously offered.

\section{CONSEQUENCES}

The lack of social workers and the professional deficits of the existing corps had major consequences for agencies and service delivery: "The impact of staff changes on service delivery is immense as there are months where the post is vacant and then time needed for the orientation of the new social worker. Much time is also spent on training which is costly when the staff member leaves a few months later." There was institutional memory loss because agencies seldom had a strong, mature core of staff. In-service training became a prime rather than supportive function. Participants suggested that one reason the child welfare field had responded by training and taking on other categories of child welfare workers was the shortage of social workers.

\section{THE MULTIPLICITY OF EMERGING PROFESSIONS}

Child welfare in South Africa was previously dominated by social workers: "It is not just social worker driven anymore. Child protection is not just a social work activity. Now organisations take responsibility for helping develop full support systems and others professionals within it". One interviewee asserted: "The way forward is a multidisciplinary workforce that assesses and works with families together... We do not have a child-focused workforce."

While participants considered it essential to develop an interdisciplinary workforce, it was clear that in addition to participants' concern regarding the shortage of social workers, the multiplicity of emerging professions in the child welfare sector was also problematic. Beyond social workers, these included social auxiliary workers, auxiliary probation officers, community workers, community development workers, child and youth care workers, and early childhood development workers. Counsellors, mediators and pastoral counsellors were further categories of personnel serving South Africa's vulnerable children and families within the child welfare sector. Some of these categories of workers are acknowledged in the Children's Act (2005), which additionally lists social security workers.

The participants identified that it was not only that a diversified workforce was being created, but that there were tensions regarding the identity and scope of practice of professional groupings. In particular, social workers were fearful that their role was being eroded and that they were potentially being replaced by less qualified, cheaper personnel. This concern has also been raised in the literature (Lombard, 2000). Although as determined by legislation, there is proportional representation of professions on the South African Council for Social Service Professions (SACSSP), one interviewee believed that the current dispute regarding appropriate 
career paths for child and youth workers was fundamentally impacted on by the SACSSP being dominated by social workers.

The lack of appropriate training, recognition, accreditation and career paths resulted in confusion and chaos, undermining the rich resource that was developing. This issue is elaborated on below.

\section{THE ROLE OF VOLUNTEERS}

Volunteers were reportedly being trained in significantly greater numbers than ever before in South African child welfare. Their role has been broadened from primarily being on boards and assisting with fundraising activities to consistently also engaging in direct service delivery. From the participants' comments, it was clear that volunteers were increasingly drawn from the communities where the majority of clients lived and were frequently themselves impoverished and had only a basic education. Volunteers and workers drawn from the communities had the advantage of being familiar to the service users and knowing the communities in which they were operating. Programmes such as Isolobantwana and Asibavikele (under Child Welfare South Africa) relied on such volunteers to identify vulnerable children (either those who have been or are at risk of abuse, or those who are affected by HIV/AIDS) and to support these children's family networks. Volunteers were an important resource: "volunteers work for small stipends ... and stay for long periods committed to the project. There is a low turnover. Most have spent at least five years in the programme. They are doing a lot of preventative work."

The findings suggested that the vital role of volunteers in delivering child welfare services had to be acknowledged, as they effectively constituted an additional player in the current South African child welfare workforce.

\section{DRIVERS BEHIND THE WORKFORCE TRENDS IDENTIFIED}

The study identified that the increased focus on recruiting and engaging a diversified workforce was related to a range of factors. Clearly, the shortage of social workers and the associated antecedents presented the most obvious challenge. However, conceptual and methodological shifts in terms of a developmental social welfare orientation were another impulse, as were changing population needs and the very existence of new cadres of child welfare staff.

As alluded to above, there have always been too few social workers to meet the expressed need. It had been critical to develop other categories of workers to respond to this shortfall. According to participants, however, the very presence of an expanded workforce was forcing agencies to seek solutions regarding the training, accreditation and acknowledgement of different categories of child welfare workers. Such a multifaceted workforce allowed the child welfare sector to respond to urgent needs. However, the inadequate structures supporting the training and recognition of these various categories of workers were in themselves leading to unbearable and unnecessary pressure on the system.

A different conceptual and methodological approach to social work and hence child welfare work had also prompted the development of an expanded workforce. The introduction of a Developmental Social Welfare model with the White Paper (1997) had required services to be conceptualised and delivered from a fundamentally different orientation to the individualised, remedial interventions that historically characterised South African welfare and child welfare. Participants stressed that community work was becoming a regular component of practice, greater efforts being made to consult with community members and locate services closer to potential clients. While casework remained important, early intervention efforts were receiving 
increased attention. The move away from an institutional bias in child welfare and the recognition by child and youth workers that children in communities can benefit from their competencies was also cited by participants as leading to a marked broadening of the selfidentified role of this category of worker.

According to the study participants, changing population needs, particularly the HIV/AIDS pandemic, appeared to have been a major driver in the expansion and diversification of a child welfare workforce. This was related to the need in the decade under discussion for finding solutions for children made vulnerable through the epidemic, which had in part expressed itself as securing financial support for families. Participants implied that more families were being ravished by poverty. Material support was increasingly being made available and a range of income-generation programmes were being initiated. These service responses required a broader array of skills than associated with clinical and casework based modes of intervention.

\section{RESPONSES TO THE ISSUES IDENTIFIED IN CREATING AN APPROPRIATE CHILD WELFARE WORKFORCE}

The workforce active in child welfare over the decade under review was unregulated, according to participants. It was not clear, for example, what minimum competencies were required, what kind of training was necessary, what salaries and working conditions should be offered, or who should accredit various professionals. Participants believed that the uncertainty and lack of direction - particularly on the part of government - was unhelpful. Participants maintained that in order to ensure a diversified, appropriate, sustainable and competent workforce various conditions had to be addressed.

\section{IMPROVING THE STATUS OF SOCIAL WORK}

While there has been much movement towards expanding the range of child welfare professionals, social workers remain a key element of such a workforce. This is affirmed by the Children's Act. A developmental social welfare orientation continues to see social workers as playing an important role in the delivery of developmental services (Patel, 2005a). Participants emphasised that it was essential that the status of social workers be improved. Sar et al. (2008) argue in a North American child welfare context that the professionalisation of social workers has been an important strategy in both improving the quality of service (and thus ensuring child safety and wellbeing) and in sustaining a stable, experienced work force. The previous attempts to increase the numbers of child welfare personnel by lowering admission qualifications, according to Sar et al. (2008: 472), resulted in the salaries decreasing and the overall status of employment in child welfare agencies being lowered, to the detriment of the sector. Because social workers with Masters degrees reportedly show greater job satisfaction, deliver higher quality work and stay in their jobs longer, Todel, Bagdasaryan and Furman (2009) urge the promotion of a career path which aims at having a highly qualified cadre of social workers.

In South Africa it must be debated whether professionalisation is the answer. Katz and Pinkerton (2003), working in the United Kingdom, argue that professionalisation may bring unintended consequences as with higher qualifications and greater specialization social workers become removed from the lived realities of the client population they intend to serve. Professionalisation is also often associated with specialisation. Specialisation may be an outcome of a highly bureaucratised child welfare system, as witnessed by the researcher in the North American context. A developmental social welfare framework is in part based on the notion of generic service delivery, because a resource-poor environment cannot afford specialisation. Furthermore, specialisation frequently results in fragmentation that is unhelpful 
for the service user. (This does not mean that developing a field of expertise is never advantageous). Another factor in the South African context is the cost of formal education, many young graduates being burdened with student debt loads. It may therefore be necessary to continue to offer study grants for formal education that are tied to service. However, as underscored by the participants, such programmes should not only benefit government, but must ensure staffing for the non-governmental sector also. Participants felt that the bursary scheme launched in recent years was important, but that there were unplanned consequences in that persons were not always committed to a career in social work, but used this as an entrance into other qualifications or professions. Screening was inadequate, hence participants recommended rigorous assessment and selection criteria. Additionally, participants highlighted that the non-profit sector did not want to be a training ground for social workers who then moved to government or entirely out of the sector. Adequate reimbursement for such investment was needed.

While the professionalisation of social workers merits discussion, the participants emphasised that appropriate accreditation was critical across the board, particularly because of historic factors: "There is a strong need in South Africa for accredited programmes due to the apartheid history and education. It is for people important to have a valid certificate for their training, as this is often linked to finding employment".

Participants were clear that salaries in the not-for-profit sector have to be much improved in order to attract and keep personnel. Local research by Briede and Loffell (2005) supports this assertion. Mkwanzi and Triegaardt (2003) found that social workers were engaged in primarily remedial work, rather than developmental activities, being unmotivated to shift their focus in part because they felt their meagre salaries and the attitudes of clients, who saw social work as hand-outs, undervalued the profession. Other working conditions also need to be better: social workers must be able to work in reasonably equipped offices, have manageable caseloads, have diversified, interesting job descriptions and be able to access their clients relatively easily. By addressing these issues, the status of social work improves resulting in a greater corps of veteran social workers.

The study suggested that retention issues be addressed, whether this was for social workers or other categories of staff. Participants referred to the Expanded Public Works Programme (EPWP), which places unskilled poor and unemployed persons into temporary positions in public and community programmes with the aim of providing both job and skills training (South African Government, undated).

"Another issue is the Expanded Public Works Programme. This means that in one of our ... programmes we have EPWP volunteers learning bakery skills and food gardening skills ... This is a mixed bag this EPWP thing, as it gives one extra workers that are paid stipends by the state, and they do manage to move onto better jobs (meaning we lose them). It is important that people gain skills and have their own income. But it raises all sorts of HR issues."

This was elaborated upon:

"As much as the creation of jobs and a workforce is very positive, it also have unintended impact on the child welfare system. For example, ECD [Early Childhood Development] practitioners and Community Health Workers that are enrolled in the EPWP [Expanded Public Works Programme] Social Sector programme, gets a stipend as part of the learnership. This stipend is often more than what they received prior to 
enrolment, which make it difficult for them to "go back" after they disengage from the EPWP. Thus, they find alternatives and are often getting better paid employment in the health sector, in Grade $\mathrm{R}$ or even as full time nannies/domestic workers. The catchtwenty-two is that the training does give the individual a key to higher employment but it depletes the sector. Though in a different context, the same applies to social workers working in the non-governmental welfare sector that leaves that part of the sector after a few years (and good training) to work for government sector due to better pay and benefits."

The research did not highlight the need to train more social workers, although this is clearly an area that must be addressed. Similarly, it is implicit that social workers representative of the populations served must be produced - a goal which has been achieved.

\section{REGULATING A CHILD WELFARE WORKFORCE}

Developmental social welfare aims beyond simply creating a multidisciplinary workforce towards one that is interdisciplinary. The interviewees feared that the development of such an integrated child welfare workforce had been chaotic and ultimately unhelpful in addressing the dire human resource shortage in the field, the problems being exacerbated by a lack of political direction and planning: "The education and training environment in the child welfare sector is complex and has varied role players, which include, SETAs, training institutions and organisations, and government departments at the very minimum." (SETAs refer to the South African Education and Training Authorities which provide apprenticeships as well as quality controls. (South African Education and Training Authority, undated)). Also of concern was that as different state departments were taking responsibility for different categories of workers, coordination and mutual support were absent. Many questions had been left unanswered:

"There is a whole debate - partly because of the list of workers in the Children's Actabout what the social service occupations are and there is the Social Services Practitioners Advocacy Network (SSPAN) and the Children's Institute in Cape Town working on this. There is a push for a less social work dominated Council [SACSSP] and a recognition of a whole range of workers. One has to have proper procedures for the registration and acknowledgement of workers and the Council failed to recognise the major tertiary qualification developed by the NACCW some years ago. It is not clear who the social service practitioner workforce should be made up of and, for example, there is disagreement as to whether probation should be treated as a specialisation of social work (as is currently the official position) or a different category of worker. So we have the [statutory] board for social workers and there has also been one for child and youth workers. ECD [Early Childhood Development] workers are nowhere in the scheme of things with the average worker not being recognised anywhere and registration by the Department of Education only for those with tertiary qualifications".

As identified by participants, a coordinated response to developing the necessary body of child welfare workers was critical.

A challenge was the difficulty ascertaining the potential human resource pool for child welfare. One interviewee concluded: "A mapping and understanding of the core functions and responsibilities of the various categories of workers in the child welfare sector will make a significant contribution in clarity, collaboration and team work in the sector, along with an appropriate funding mechanism." While there is undoubtedly intersection between professions, 
minimal skills sets and competencies must be defined for each professional category (as has been done for social work and child and youth work (Booyens, 2000). This is especially important as the roles and competencies of various occupations are not clear, the professions developing in response to a variety of needs and in a range of contexts, but without appropriate guidelines. Not only must the framework for the recognition of various categories of child welfare personnel be developed, but questions of professional identity must also be addressed. Role boundaries do become diffuse in interdisciplinary work. For professionals to feel competent and to make a positive contribution in an interdisciplinary team, a generic orientation is required, while simultaneously having a solid foundation and confidence in one's particular field of expertise.

The participants suggested it was imperative to regulate the child welfare workforce, two steps being required: the accreditation of various courses and the formal acknowledgement of particular categories of child welfare workers. For example, "Community care workers first emerged and they want recognition. They need more than a stipend ... Accredited training is absolutely necessary as a next step". A related problem was that subsidies could not be claimed for workers who were not formally acknowledged. Participants recommended clear educational and career paths. Those entering the field with basic skills should have the opportunity for deepening and advancing their qualifications and a recognised career path to follow in order to maintain motivation as well as excellence. One interviewee declared: "We identify volunteers with aptitude and ability and facilitate their access as social workers, community development workers, child and youth care workers, ECD [Early Childhood Development] workers. In this way we keep child protection professional...The trend is therefore towards expanding the knowledge base and also developing the workforce and so expanding the social service net...".

Developing an interdisciplinary workforce may require that the career path that occupational groupings follow is not simply a hierarchical one, with social workers with Masters degrees at the top of the pile. Though social auxiliary workers do function as assistants to social workers and can develop their careers in that direction, child and youth workers, for example, have a distinctive skill set and are not mini-social workers. Caution is needed not to create a myriad of specialisations and parallel career paths as this potentially leads to fragmentation, though Pozzuto (2001) has observed that greater professionalisation of social workers leads to increased normalisation and so insists that diversity within a welfare workforce is necessary. Frost and Parton (2009) observe that social workers can benefit from interdisciplinary teams when they are confident of their professional identity, adopt a "social care" or holistic perspective, and are open to learning from others. It would appear a balance needs to be found.

\section{DEVELOPING A RELEVANT TRAINING MODEL}

The interview responses stressed the need for policy direction regarding the education of a child welfare workforce, this having been an important debate in the decade researched. While the SACSSP has developed responses to the workforce crisis, the participants' frustration at the lack on the part of government and the SACSSP regarding both clarity and movement towards a coherent workforce was patent. Political agendas also appeared to be in conflict, while consultation with the non-governmental sector was lacking or recommendations overlooked.

Participants insisted that training initiatives were largely uncoordinated, different imperatives emerging from various parts of the child welfare sector, various categories of personnel being developed in diverse but unrelated programmes and training not being standardised. Sar et al. (2008) explain that training can occur at two points of professional development: basic 
foundational training and continuing education. Training can be offered as pre-service (as a prerequisite to practice) or as in-service (accompanying service delivery). They further maintain that, should studying and work accompany each other, it is critical that the employer acknowledges the importance of the training; accommodates the study demands on the employee; and accepts the final qualification or accreditation. Ongoing professional development may take the form of courses or supervision. As noted earlier, the participants emphasised the central role of quality supervision in ensuring effective service delivery and maintained that all child welfare workers, but neophytes in particular, required the technical and emotional support of a qualified supervisor who could act as a role model. Participants believed a key focus of retention policies in the South African context had to be to keep employees with experience in the workforce and to train and support them to be supervisors.

The participants stressed that training needed to be relevant. This in part meant that a holistic, generic orientation was needed. Furthermore, participants highlighted the importance of developing relevant indigenous expertise ("It is important that we do not import training from other countries, especially from outside Africa. An indigenous approach to social welfare services is important"). Indigenous training materials also were needed, the interviewees noting that some local initiatives - for example, training offered by the University of KwaZuluNatal - could be further developed. Developing indigenous responses has also been identified as a priority area in the literature (Gray, 2005).

Practitioners elaborated on the disjuncture between the university training received by social work students and the needs in the field, though academics believe they equip students for practice on the ground. Sar et al. (2008) note that universities aim to deliver broad-based education, while agencies have immediate needs that should be satisfied. Although this is a universally recognised gap, it is nevertheless a matter of concern. Academics in the study identified their dilemma: do they train students primarily in case work as the demands particularly in child welfare remain casework driven, or do they train students according to national welfare policy in developmental social welfare (DSW)? While the SACSSP is strongly committed to developmental social welfare, this body suggests that it remains valid to offer significant case work training. It would seem that instructors need to explicitly manage the complexity and tensions in DSW. For example, Lund (2008:150) maintains that students must understand how the provision of grants is integral to the socio-economic synergy that developmental social welfare aims to achieve and should "continue to claim ... space for therapeutic intervention practice, for continuing with the healing role that is so badly needed in our fractured and violent society". This position is supported by Midgely (2011), who argues case work has a place within developmental social welfare. For educational institutions to determine a child welfare curriculum, it becomes critical to develop a developmental child welfare model that, amongst other issues, identifies the form and content of individual interventions within such a model. This may be complemented by considering transdisciplinary work. This approach, which permits insight into multiple professional perspectives, allows for the integration of the social and environmental, and strengthens university-community partnerships (Tourse et al., 2008). Critical reflexive practice, in which power dynamics between service providers as well as between service providers and recipients, are interrogated is also important. These are approaches which universities are increasingly introducing.

An issue in the study was who should be responsible for training and developing this cadre of child welfare professionals. At least two of the agencies represented by the interviewees were in the process of developing training facilities, arguing they had the on-the-ground experience 
and could provide platforms for the integration of theory and practice. While this is true, the educational expertise lies with the tertiary educational institutions. At the very least, training efforts must be implemented in partnership with these educational facilities. At best, educational institutions should offer the necessary training to all levels of the child welfare workforce with active involvement of the child welfare agencies. Indeed, Van Delft (2000:155) notes that the "Future relevance of social work as a profession and as an academic discipline is dependent on the development of a mutually empowering partnership between social welfare organizations and university departments of social work". This is supported by Patel (2005b), who maintains that curriculum needs to be reformed towards a social development orientation if social workers are to be able to implement this approach and that research agendas should also be constructed with this perspective in mind.

\section{THE ROLE OF VOLUNTEERS}

When considering a child welfare workforce, participants suggested it is imperative to explicitly define who volunteers are as well as to articulate the role of volunteers and where they fit into the broader workforce. Volunteers have historically been active in the child welfare sector. However, as indicated in this study, this role appears to have taken on new significance. Are volunteers simply the bottom of the pile, cheap labour, who may have the opportunity of being trained up into other levels of the workforce? Or do they make a uniquely particular contribution? Volunteer training programmes are becoming increasingly formalised and standardised. Bonfleur (2008) emphasises that training of volunteers is vital. Such training, though, leads to further demands as, according to participants, volunteers frequently wished their skills to be formally acknowledged and wanted to upgrade their qualifications. This must be taken into account. "One cannot have volunteerism in a context of poverty - this creates problems. People have aspirations". A further question which arises is how the payment of stipends affects how a volunteer is defined and how volunteerism is experienced.

These issues are receiving some attention from government, but how volunteers are now being constructed also causes difficulties for the participants:

"The term volunteer no longer means what it used to. The Department of Labour has come out with new draft labour legislation that would make volunteers part of the labour force with the same rights and with a minimum stipend. We even have people wanting to be paid salaries on boards-so the meaning of volunteerism is being entirely eroded, though of course one wants to ensure that volunteers are not taken advantage of. The Unions say volunteers are a crooked way of getting cheap labour. But if we had the resources to employ people we would do so. Perhaps the EPWP people should be called interns - this is what the [welfare] Forum is talking about recommending".

A critical review of volunteerism in South Africa is required; for example, reviewing what motivates volunteers; what they need to stay in these positions; when they feel they are being exploited; and why agencies utilise volunteers instead of paid labour.

A number of factors are therefore prompting the consideration of an expanded child welfare workforce that includes categories of service providers beyond social workers. It is apparent that a de facto expanded workforce exists, and that alongside social workers, there are also community workers, youth workers, child and youth workers, social auxiliary workers and others who are delivering services to South Africa's vulnerable children and families. 


\section{CONCLUSION}

As noted by one interviewee: "If we don't direct the workforce, people will do this themselves. Health, being more strongly organised, will steal the show. It results in ad hoc development and creates problems".

The role of the government is central to the development of a sustainable, coherent workforce. The frustration on the part of participants suggests that greater urgency is required in attending to these issues. The response of the SACSSP needs to be scaled up. The categories that are needed for an effective child welfare workforce must be identified, though standards should nevertheless allow for a flexible workforce. In addition, the SACSSP must (in accordance with its mandate), in cooperation with service providers and academic institutions, develop minimum requirements and determine who can offer training under which conditions. The government must also anticipate unintended consequences of policies. As noted earlier, participants believe that the bursary scheme initiated by government as part of its retention and recruitment strategy, while important, allowed the entry of students who are not seeking a career in social work. Additionally, the introduction of the EPWP unintentionally weakened the sector.

Participants made it clear that a united welfare sector would be able to put pressure on the state to introduce the necessary changes as groupings with political clout were more likely to get recognition such as the "well-organised community development workers". The voices of the national councils, but also of regional and national welfare forums, were seen as critical. Consolidated action by professional groupings was also important: "In child and youth care there is no longer major discussion, we are united. Social work has now got one organisation but this came from the top down".

Educational institutions are the third role player. These facilities have to work in concert with agencies to ensure that child welfare workers are indeed able to implement effective service delivery.

Child welfare agencies dominate the South African welfare scene. The issues of relevance for the child welfare arena are therefore important to consider in welfare more broadly. The human resource problems in South African welfare, and by association, child welfare, have in the past typically been identified as a shortage of qualified social workers. What emerged from the study is the urgent need not only to improve the numbers and quality of social workers in the field, but to expand the child welfare workforce to include other service providers. Additionally, the regulation of training, accreditation and working conditions is necessary.

It appears from this study that the emergence of a broader child welfare workforce is in part a response to the demographic realities evidenced in the decade under review, but also partly a response to the Developmental Social Welfare policy articulated in the 1997 White Paper. While there are clear challenges in formalising and regulating the myriad of service providers now active in the child welfare field, it is also exciting to recognise the initiative of South Africans in addressing the needs of vulnerable children and families in a context of development. 


\section{REFERENCES}

ALVESSON, M. \& SKOLDBERG, K. 2000. Reflexive methodology. Thousand Oaks, CA: Sage Publications.

ANDERSSON, G. 2006. Child and family welfare in Sweden. In: FREYMOND, N. \& CAMERON, G. Towards positive systems of child and family welfare: international comparisons of child protection, family service and community caring systems. Toronto: University of Toronto Press.

BOOYENS, M. 2000. The development of a bachelor's degree in youth work: a process with a difference. Social Work Practitioner, 12(2):93-112.

BONFLEUR, C. 2008. The network of human solidarity: volunteering and child wellbeing in Brazil. The Social Work Practitioner-Researcher, 20(1):124-129.

BRIEDE, M., \& LOFFELL, J.(2005). Making social work workable. Children First, 61(May/June). [Online] www.childrenfirst.org.za [Retrieved: 09/07/2005]. (This website has been discontinued.)

FREYMOND, N. \& CAMERON, G. 2006. Towards positive systems of child and family welfare: International comparisons of child protection, family service and community caring systems. Toronto: University of Toronto Press.

FROST, N. \& PARTON, N. 2009. Understanding children's social care. London: Sage Publications.

GRAY, M. 2005. Dilemma of international social work: paradoxical processes in indigenization, universalism and imperialism. International Journal of Social Welfare, $14: 231-238$.

KATZ, I. \& PINKERTON, J. (eds) 2003. Evaluating family support: thinking internationally, thinking critically. Chichester: John Wiley \& Sons.

LOMBARD, A. 2000. The professional status of social work. Social Work/Maatskaplike Werk, 36(4):311-331.

LUND, F. 2008. Paradoxes of social policy reform in South Africa. The Social Work Practitioner-Researcher, 20(2):137-153.

MELPIGNANO, M. \& COLLINS, M. 2003. Infusing youth development principles in child welfare practice: use of a Delphi survey to inform theory. Child and Youth Care Forum, 32(3):159-173.

MIDGLEY, J. 2010. The theory and practice of developmental social work. In: MIDGLEY, J. \& CONLEY, A. (eds) Social work and social development: theories and skills for developmental social work. New York: Oxford University Press, 3-30.

MKWANZI, H. \& TRIEGAARDT, H. 2003. Reconceptualisation of social work: a study in Johannesburg. The Social Work Practitioner-Researcher, 15(1):48-60.

PATEL, L. 2005a. Social welfare and social development in South Africa. South Africa: Oxford University Press.

PATEL, L. 2005b. Social development and curriculum renewal in an African context. The Social Work Practitioner-Researcher, 17(3):363-377. 
POZZUTO, R. 2001. Lessons in continuation and transformation: the United States and South Africa. Social Work/Maatskaplike Werk, 37(2):154-164.

REPUBLIC OF SOUTH AFRICA. 2005. Children's Act: No 38 of 2005 Government Gazette, 492 (28944). Pretoria: Government Printers.

SAR, B., BLEDSOE, L., SULliVAN, D., WEEKS, P., FOX, S., BARRETT, L., WADLINGTON, K. \& CASHWELL, Z. 2008. Professionalising the child welfare workforce: Kentucky's Credit for Learning (CFL) initiative. Journal of Public Child Welfare, 2(4):471494.

SCHMID, J. 2010. A history of the present: uncovering discourses in (South African) child welfare. British Journal of Social Work, 40(7):2102-2118; doi: 10.1093/bjsw/bcp124.

SOUTH AFRICAN GOVERNMENT. undated. Welcome to the Expanded Public Works Programme (EPWP): Phase 2. [Online] Available: http://www.epwp.gov.za/ [Retrieved: $10 / 04 / 2012$.

SOUTH AFRICAN SKILLS EDUCATION AND TRAINING AUTHORITY. undated. I Education SETA South Africa. [Online] Available: http://www.vocational.co.za/ Retrieved: $10 / 04 / 2012$.

TODEL, F., BOGDASARYANN, S. \& FURMAN, W. 2009. A multivariate analysis of training, education and readiness for public child welfare practice. Children and Youth Services Review, 31(12):1330-1336.

TOURSE, R., MOONEY, J., SHINDUL-ROTHSCHILD, J., PRINCE,J., PULCINI, J., PLATT, S. \& SAVRANKSY, H. 2008. The university-community partnership: Transdisciplinary course development. Journal of Interprofessional Care, 22(5):461-474.

VAN DELFT, W. 2000. A mutually empowering partnership between social welfare organizations and universities in South Africa- a new challenge. Social Work PractitionerResearcher, 12(3):155-164.

Dr Jeanette Schmid, Research Fellow, Centre for Social Development in Africa, University of Johannesburg, Johannesburg, South Africa. 